\title{
Modelo de vulnerabilidade em saúde: esclarecimento conceitual na perspectiva do sujeito-social
}

Health vulnerability model: conceptual clarification from social subjects' perspective Modelo de vulnerabilidad en salud: esclarecimiento conceptual en la perspectiva del sujeto social

\author{
Raquel Sampaio Florêncio ${ }^{1}$ io https://orcid.org/0000-0003-3119-7187 \\ Thereza Maria Magalhães Moreira ${ }^{1}$ io https://orcid.org/0000-0003-1424-0649
}

\section{Como citar:}

Florêncio RS, Moreira TM. Modelo de vulnerabilidade em saúde: esclarecimento conceitual na perspectiva do sujeito-social. Acta Paul Enferm. 2021;34:eAPE00353.

DOI

http://dx.doi.org/10.37689/actaape/2021A000353

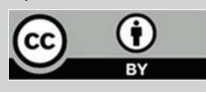

Descritores

Vulnerabilidade em saúde; Saúde pública; Modelos teóricos; Formação de conceito; Vulnerabilidade social; Promoção da saúde

Keywords

Health vulnerability; Pubic Health; Models, theoretical; Concept formation; Social vulnerability; Health promotion

Descriptores Vulnerabilidad en salud: Salud pública; Modeos teóricos; Formación de concepto; Social vulnabilidad; Promoción de la salud

Submetido 25 de Fevereiro de 2020

Aceito

20 de Outubro de 2020

\section{Autor correspondente}

Raquel Sampaio Florêncio

E-mail: raquelsampy@hotmail.com

\section{Resumo}

Objetivo: Esclarecer a vulnerabilidade em saúde a partir da proposição de um modelo conceitual.

Métodos: Aplicou-se o esclarecimento de conceito segundo proposta de Meleis, subsidiado por revisão e por reflexão crítica. Selecionaram-se 101 artigos em cinco base de dados por meio da equação de busca "vulnerability" AND "health", cujos achados foram submetidos à análise categorial e de similitude. Essa foi processada no software Iramuteq para identificação do elemento essencial, conceitos e subconceitos da vulnerabilidade em saúde - e posterior construção de um modelo.

Resultados: A partir da revisão e etapas posteriores, a vulnerabilidade em saúde foi redefinida, e foi construído um modelo com base na relação de três componentes: 1) 0 sujeito-social, com seus conceitos e subconceitos; 2) A condição de precariedade e agenciamento; 3) Processos de potencialização ou fragilização da vulnerabilidade em saúde. 0 fenômeno foi descrito, identificando-se 0 sujeito-social como elemento essencial, e foram conhecidos os principais atributos com as definições constitutivas e operacionais, tornando possível identificar a presença da vulnerabilidade em saúde.

Conclusão: 0 conceito foi esclarecido por meio da construção de um modelo, fornecendo subsídios à elaboração de pesquisas na área da saúde e ao futuro desenvolvimento de teorias de médio ou longo alcance do fenômeno de interesse.

\section{Abstract}

Objective: To clarify health vulnerability from the proposition of a conceptual model.

Methods: Concept clarification was applied according to Meleis' proposal, supported by review and critical reflection. 101 articles were selected in five databases using the search equation "vulnerability" AND "health", whose findings were submitted to category and similar analysis. This was processed in the software Iramuteq to identify the essential element, concepts and subconcepts of vulnerability in health - and later construction of a model.

Results: From the review and later stages, health vulnerability was redefined and a model was constructed based on the relationship of three components: 1) The social subject, with its concepts and subconcepts; 2) The condition of precariousness and agency; 3) Processes of potentiation or weakening of vulnerability in health. The phenomenon was described, the social subject was identified as an essential element, and the main attributes were known with constitutive and operational definitions, making it possible to identify the presence of vulnerability in health.

Conclusion: The concept was clarified through the construction of a model, providing support for the elaboration of research in the health area and future development of medium or long-range theories of the phenomenon of interest. 


\section{Resumen}

Objetivo: Esclarecer la vulnerabilidad en salud a partir de la proposición de un modelo conceptual.

Métodos: Se aplicó el esclarecimiento de concepto según la propuesta de Meleis, respaldado con revisión y reflexión crítica. Se seleccionaron 101 artículos en cinco bases de datos por medio de la ecuación de búsqueda "vulnerability" AND "health", cuyos resultados fueron sometidos al análisis categorial y de similitud. Este fue procesado con el software Iramuteq para la identificación del elemento esencial, conceptos y subconceptos de la vulnerabilidad en salud y la posterior construcción de un modelo.

Resultados: A partir de la revisión y etapas posteriores, la vulnerabilidad en salud fue redefinida y se construyó un modelo basado en la relación de tres componentes: 1) El sujeto social, con sus conceptos y subconceptos, 2) La condición de precariedad y gestión, 3) Procesos de potencialización o debilitamiento de la vulnerabilidad en salud. El fenómeno se describió con la identificación del sujeto social como elemento esencial y se conocieron los principales atributos con las definiciones constitutivas y operativas, lo que permitió identificar la presencia de la vulnerabilidad en salud.

Conclusión: El concepto fue esclarecido mediante la construcción de un modelo y respalda la elaboración de estudios en el área de la salud y el desarrollo futuro de teorías de medio o largo alcance del fenómeno de interés.

\section{Introdução}

O termo vulnerabilidade, já usado há algum tempo em diversas situaçóes, foi incorporado ao discurso e às práticas na área da saúde, com vistas a uma leitura mais compreensiva dos complexos processos de saúde e enfermidade e, portanto, auxiliadora de respostas sociais mais efetivas e integrais. Ressaltase que a preocupação com a vulnerabilidade encontrou plena vigência no campo da saúde a partir da década de 1980, época da epidemia da Acquired Immunodeficiency Syndrome (AIDS). ${ }^{(1)}$

Após, começou-se a utilizar o conceito vulnerabilidade em saúde (VS) como referencial para as discussôes realizadas no campo científico de diversas temáticas e com diferentes sentidos, cuja diversidade de aplicaçóes se deve a algumas situaçóes, em especial: à existência de diferentes orientaçóes epistemológicas; à escolha de localidades geográficas para a análise do processo de vulnerabilidade; ao direcionamento para situaçóes específicas. ${ }^{(2-4)}$

$O$ termo abrange ainda uma série de qualificaçóes, cujas definiçōes apresentam especificidades. Essas concepções são fomentadas em diversas áreas do conhecimento, trazendo em comum o fato de que a VS está sempre ocorrendo no território onde as pessoas vivem. ${ }^{(3)}$ Esse uso estendido do conceito direciona caminhos e perspectivas para ambiguidades e contradiçóes, ${ }^{(1,4)}$ requisitando definições novas ou complementares e reflexóes acerca do conceito, que se revela amplo, complexo e subjetivo. ${ }^{(5)}$

Em uma análise crítica dos referenciais de VS, percebeu-se que os quadros conceituais ${ }^{(4,6)}$ mais utilizados não trazem definições dos elementos relacionados aos conceitos e subconceitos, fazendo-se necessário esclarecimento conceitual para contribuir para a construçáo do arcabouço teórico sobre o tema e para propiciar o desenvolvimento de um modelo conceitual para identificação, avaliação e intervençáo nas situaçóes de vulnerabilidade pelos profissionais de saúde. É sabido que não foi objetivo dos autores ${ }^{(4,6)}$ a construção de uma teoria sobre VS, mas pensar o conceito, aproximando-o e ligando-o à promoção da saúde e, no caso do referencial brasileiro, considerando princípios da hermenêutica. Desse modo, seus escritos prévios forneceram a base para a construçáo de um modelo conceitual de VS ao indicar como outros conceitos poderiam ser articulados.

Para esses autores, ${ }^{(4,6)}$ a VS compreende a perspectiva ética de diferentes graus e naturezas de suscetibilidade de indivíduos e coletividades que os levam ao sofrimento, adoecimento/agravo e finitude, segundo particularidades formadas pelo conjunto de aspectos sociais, programáticos e individuais, que os póem em relação com o problema e com os recursos para seu enfrentamento. A partir dessa definiçáo e de seus usos, compreende-se que há um campo aberto para repensar, redefinir e propor formas de utilização da VS.

Definir, esclarecer, avaliar, operacionalizar e submeter conceitos a avaliaçóes teóricas e empíricas são processos essenciais e vitais no avanço do conhecimento. $\mathrm{O}$ desenvolvimento de conceito $^{(7)}$ apresenta cinco níveis: exploração, esclarecimento, análise e abordagem integrada. Neste estudo, traz-se o segundo nível, pois o conceito VS já existe, mas não está compreensível nas publicaçôes, pois diversos significados são apontados com contradições quanto aos referenciais originais. Desse modo, 
foi objetivo deste estudo esclarecer a VS a partir da proposição de um modelo conceitual.

\section{Métodos}

O estudo foi desenhado considerando as etapas adaptadas do esclarecimento conceitual conforme Meleis $^{(7)}$ em articulação com uma revisão ${ }^{(8,9)}$ e sua posterior atualização.

Como forma de proceder a execução da pesquisa, estabeleceram-se as principais questôes a serem respondidas em correspondência com as fases do referencial metodológico. Reitera-se que, para este estudo, foram consideradas as fases dois a cinco, onde a primeira foi desenvolvida em estudo anterior. ${ }^{(8,9)}$

Logo após a definição das questóes, buscaram-se artigos publicados nas bases de dados Literatura Latino-Americana e do Caribe em Ciências da Saúde (LILACS), Índice Bibliográfico Espanhol de Ciências da Saúde (IBECS), Base de dados da Enfermagem (BDENF), Cumulative Index to Nursing and Allied Health Literature (CINAHL) e no portal PUBMED. Utilizaram-se, na busca às publicações nas bases de dados, as palavras-chave contidas na seguinte equação de busca: "vulnerability" AND "health". Essa equação foi utilizada em todos os momentos da coleta e em todas as fontes. A busca final ocorreu em dezembro de 2019, com a atualização do estudo original.

Foram incluídos artigos contendo o termo 'vulnerabilidade' no título, sem limite de data e disponíveis eletronicamente na íntegra. Excluíram-se estudos sem definição explícita de VS, com literatura cinza, estudos teóricos, de caso e estudos de revisão. ${ }^{(8)}$

A busca foi realizada por dois pesquisadores, e executou-se o processo de seleção dos estudos a partir de uma leitura minuciosa de títulos e resumos de modo que foram para a seleção final aqueles que atenderam aos critérios de inclusão e exclusão citados. A partir da equação de busca, 27.035 publicaçóes foram encontradas, das quais 26.934 não atenderam aos critérios: 7.873 devido a duplicaçôes; 15.083 , por não ter vulnerabilidade no título; 1.819 , por não conter texto completo; 316 , por não ter definição explícita de VS; 1.572, por não abordavam VS; 271, por serem literatura cinza. Desse total, selecionaram-se 101 artigos para leitura completa e análise (Quadro 1).

Quadro 1. Correspondência entre as fases do esclarecimento conceitual e as questões norteadoras do estudo

\begin{tabular}{|l|l|}
\hline Fase da clarificação & Questão norteadora \\
\hline $\begin{array}{l}\text { 1 - Descrição do fenômeno inerente ao } \\
\text { conceito }\end{array}$ & $\begin{array}{l}\text { Quais as características dos estudos que } \\
\text { foram publicados sobre o tema? } \\
\text { Quais são os significados e usos da } \\
\text { vulnerabilidade em saúde descrita pelos } \\
\text { estudos? }\end{array}$ \\
\hline $\begin{array}{l}\text { 2 - Sistematização das observações e das } \\
\text { descrições do fenômeno }\end{array}$ & $\begin{array}{l}\text { Quais os elementos essenciais do conceito } \\
\text { de vulnerabilidade em saúde? } \\
\text { Quais são os processos ou situações } \\
\text { produzidas pela vulnerabilidade? }\end{array}$ \\
\hline $\begin{array}{l}3 \text { - Desenvolvimento das definições } \\
\text { constitutivas e operacionais, e pergunta a si } \\
\text { mesmo e aos outros: Como vou conhecer 0 } \\
\text { conceito quando 0 'vejo'? }\end{array}$ & $\begin{array}{l}\text { Quais características/atributos são apontados } \\
\text { como referentes ao conceito e contribuem } \\
\text { para o seu reconhecimento? }\end{array}$ \\
\hline 4 - Construção do modelo & $\begin{array}{l}\text { Qual a relação entre os conceitos e } \\
\text { subconceitos que permitem a construção } \\
\text { de um modelo conceitual que clarifica a } \\
\text { vulnerabilidade em saúde? }\end{array}$ \\
\hline 5 - Desenvolvimento de pressupostos &
\end{tabular}

De acordo com os aspectos de um roteiro de observação, as publicações e os dados dos 101 artigos foram interpretados de forma organizada e sintetizada por meio de um quadro sinóptico com a descrição dos seguintes aspectos gerais dos artigos: autor, temática, revista, ano, tipo de estudo e local. ${ }^{(8)}$

Inicialmente, foram construídas categorias analisadas com base na estatística descritiva para quantificar os aspectos gerais e metodológicos das publicaçôes. Posteriormente, identificaram-se as definiçôes de VS e os principais resultados dos artigos. A partir da leitura minuciosa, foram realizadas análises críticas, e foram extraídas as definiçôes de VS, que constituíram o corpus principal do estudo. Utilizou-se o software Interface de R pour les Analyses Multidimensionnelles de Textes et de Questionnaires (IRAMUTEQ) para auxílio na fase de análise da similitude, com o objetivo de identificar os elementos essenciais da VS a partir das definiçôes.

No que se refere às inspiraçóes do conceito, essas já foram contempladas em outras ocasiōes. ${ }^{(4,6)}$ Ademais, neste estudo, partiu-se do pressuposto que o fenômeno da VS não tem antecedentes que o desencadeiam, pois náo se trata de causa e efeito. Assim, definiram-se os elementos constitutivos e operacionais (relacionados ao elemento essencial, conceitos e subconceitos) para permitir para iden- 
tificação da VS por ocasião de sua presença, bem como as situaçóes produzidas pela VS. Para tanto, ficharam-se os artigos, e após a extraçáo dos principais recortes dos resultados, esses foram categorizados pelas palavras-chave semelhantes e recategorizados até resultarem nos atributos, suas definições e produção envolvida na VS (precariedade ou agenciamento).

Atributos são palavras ou expressóes que aparecem repetidamente na literatura, que mostram a essência do conceito. Constituem características que expressam o conceito, que atuam como elementos diferenciais para discriminar o que é e o que não é presença do conceito. Quando ele é muito abstrato, seus atributos têm também alto grau de abstração. Já a definição constitutiva é concebida em termos de conceitos próprios da teoria em que ele se insere. Por fim, a definição é operacional quando há definiçãa, não mais em termos de outros conceitos, mas em termos de operaçôes concretas, isto é, de comportamentos, atitudes ou sensaçôes pelos quais o construto se expressa. ${ }^{(7,10)}$

Assim, deu-se início à construção do modelo conceitual de VS. Ele foi desenvolvido pela reflexão crítica dos resultados das etapas anteriores, e deu-se visibilidade aos elementos essenciais, seus conceitos e subconceitos relacionados, bem como ao produto dessas relaçóes e suas articulaçóes. Por fim, esse processo teve três etapas: construção teórica (realizada em todas as etapas anteriores da clarificação), desenho do modelo (utilizando recursos artísticos: desenho gráfico com elementos da música), sua explicação e reflexão.

\section{Resultados}

Para a fase da sistematização das observaçóes e das descriçôes do fenômeno, chegou-se à figura 1, a qual mostrou que, num primeiro momento, os elementos essenciais do conceito eram constituídos do individual e do social. No entanto, após análise reflexiva, interpretou-se como sujeito e social.

Para contextualizar esses achados, compreendeu-se que esses elementos essenciais correspondem aos atributos/características da VS, os quais são



Figura 1. Elementos essenciais do conceito de vulnerabilidade de acordo com a revisão

sustentados por outros conceitos e subconceitos. A partir dos quadros prévios, houve recategorização, sendo atribuída uma definição constitutiva e operacional para facilitar o entendimento de como identificar situações de VS (Apêndice 1). Alguns permaneceram como previamente pensado, outros foram agrupados e outros modificados.

$\mathrm{O}$ quadro 2 representa uma síntese dos conceitos e subconceitos que compóem os elementos essenciais da VS e suas definições.

Além da necessidade da apresentação dessas definições, entendeu-se que haveria uma resposta na vivência desses aspectos que poderia produzir ou se confundir com condiçóes de precariedade ou agenciamento. Nos estudos que apontam a precariedade, ela tem cenários diversos, e a violência é uma condição expressiva discutida. Mas existe a possibilidade de mudança de direção desses processos, sendo o agenciamento responsável por isso. Vários aspectos favoreceram essa condição, como redes de apoio, enfrentamentos, reflexóes, espiritualidade, sentimentos positivos e práticas de promoção da saúde.

Desse modo, a partir da articulação e da reflexão dos elementos da revisão, compreendeu-se a VS como uma condição da vida humana expressa em todas as suas dimensões a partir dos (re)arranjos das relaçóes de poder que constituem o sujeito-social, produzindo precariedade quando os movimentos de agenciamento não são potencializados para a promoção da saúde.

Ademais, na figura 2, pôde-se observar os principais componentes do modelo conceitual da VS 
Quadro 2. Definições dos elementos essenciais e respectivos conceitos e subconceitos da VS

\begin{tabular}{|c|c|}
\hline \multicolumn{2}{|c|}{$\begin{array}{l}\text { Sujeito } \\
\text { Vida humana constituída a partir das relações intersubjetivas, onde há espaço para a manifestação da liberdade no tensionamento entre saber e poder e para possibilidades de recriação de si. }\end{array}$} \\
\hline Letramento funcional & Aprendizagem, Cognição, Conhecimento, Escolaridade \\
\hline Comportamento & Atitude, Autocuidado, Estilo de vida, Práticas no trabalho, Rotina e cotidiano, Comunicação \\
\hline Relações interpessoais & Relações familiares, Relações de amizade, Relações de trabalho, Relações afetivo-sexuais \\
\hline Situação psico-emocional & Autoestima, Aceitação, Concentração, Crenças, Desejos, Orientação sexual, Saúde mental, Percepções, Sentimentos, Valores \\
\hline Situação física & Idade, Sexo, Raça/cor, Aspectos físicos relacionados ao trabalho, Impacto da doença no trabalho, Situação de saúde-doença \\
\hline \multicolumn{2}{|c|}{$\begin{array}{c}\text { Social } \\
\begin{array}{c}\text { Cena de aparição que pressupõe as diferentes formas do sujeito se relacionar com outras vidas ou instituições no campo da saúde; é o espaço de se expressar, de se reconhecer e de } \\
\text { reconhecimento pelo e com o outro. }\end{array}\end{array}$} \\
\hline Situação socioeconômica & Bens materiais, Moradia, Renda, Classe social, Trabalho, Educação \\
\hline Identidade demográfica & Etnia, Procedência, Migração \\
\hline Cultura & Formação cultural, Construções sociais, Diferenças culturais, Saber popular \\
\hline Contexto familiar & Situação conjugal/familiar, Característica dos membros, Tipos de família \\
\hline Redes e suportes sociais & Apoio social \\
\hline Gênero & Desigualdade de gênero, Papéis tradicionais, Machismo \\
\hline Violência & Discriminação, Violência sexual, Violência física, Violência verbal, Violência psicológica \\
\hline Controle social & Participação social \\
\hline Ecossistema & Resíduos, Ambiente, Clima \\
\hline Acesso aos direitos fundamentais & Direitos fundamentais de primeira, segunda, terceira e quarta gerações \\
\hline Situação programática - ênfase na saúde & Infraestrutura, Processo de trabalho \\
\hline Estado & Políticas públicas, Financiamento \\
\hline
\end{tabular}

e sua relação, resgatando: 1) $\mathrm{O}$ sujeito-social, com seus conceitos e subconceitos; 2) A condição de precariedade e agenciamento; 3) Processos de potencialização ou fragilização da VS.

A figura 2 mostra uma relação dos elementos sujeito e social, com seus principais conceitos, em relação íntima, que configura, em conjunto com a precariedade e agenciamento, os processos de VS. Esses assumem várias nuances e reconfiguram novamente a VS, em um contínuo de movimentos diversos e em multiplicidades decorrentes das tensóes produzidas nas relaçóes entre o sujeito-social, seu elemento essencial.

\section{Discussão}

Autores de referência ${ }^{(4,6)}$ consideraram que a VS se constituía por duas dimensôes (individual e contextual) e três dimensóes (individual, social e programática). Com base nos resultados apresentados pelo IRAMUTEQ, a partir da análise de similitude, identificou-se a estrutura, o núcleo central e o sistema periférico da interpretação da VS, na qual os dois grandes eixos organizadores são o individual e o social. Esses elementos passaram por uma análise crítica, ou seja, aproximação do conteúdo com ideias de sujeito de Michel Foucault e Judith Butler,

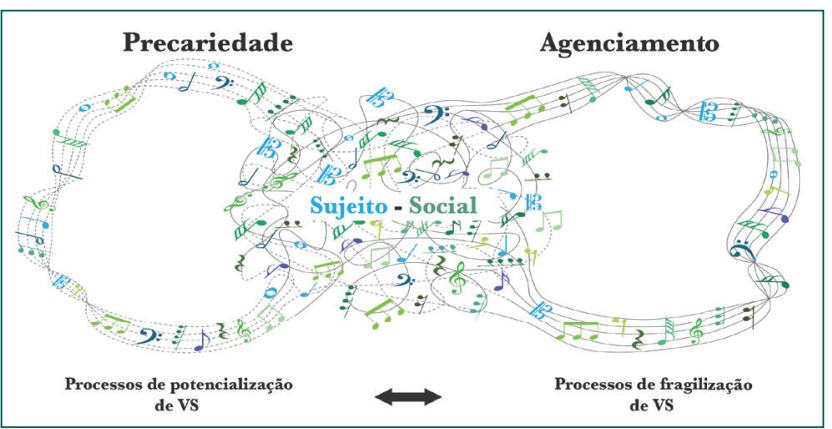

Figura 2. Modelo conceitual da vulnerabilidade em saúde

onde o individual passou a ser a dimensão do sujeito e o social permaneceu como tal, conforme as categorias analíticas dos artigos.

Essa adaptação ocorreu, pois entende-se que o sujeito é um produto das relaçóes de poder, é formado e constituído por ele, não seu produtor. Inexiste um sujeito essencial que estaria alienado por ideologias, por relaçóes de poder que encobririam sua visão da realidade. ${ }^{(11-15)}$ Se pensarmos que o sujeito está sempre nesse movimento, seria controverso chamá-lo de indivíduo, pois esse termo denota desconexão. Quando pensamos em poder, pensamos em relação. Se ao mesmo tempo ele proíbe e induz, censura e produz (discursos, verdades e realidades), se ele afeta e é afetado, podemos entender que o poder só existe na relação, o poder é por natureza relacional, é um poder em movimento. ${ }^{(11-15)}$ 
Assim, caracterizados os elementos essenciais separadamente, os quais foram posteriormente entendidos como sujeito-social, foi-se em busca de seus conceitos e subconceitos, como forma de identificar a VS quando ela acontece. Esses estimulam a reflexão sobre as relaçóes de poder como efeitos hegemônicos de posiçôes estratégicas continuamente sustentadas e os afrontamentos, entendidos como o confronto das forças sociais em antagonismo constante às posições estratégicas instituídas. Estão articulados conforme suas definiçôes operacionais que demonstram como as situações de VS podem estar sendo vivenciadas e produzidas.

No entendimento da VS, a relação de poder entre o sujeito e o social é um campo aberto de respostas, reaçôes, resultados e possíveis invenções. Assim, entende-se haver uma resposta que pode produzir condiçóes de precariedade ou agenciamento.

A condição de precariedade pode se revestir de diferentes formas, desde o início, manutenção ou complicação de uma doença, até, por exemplo, afetar a qualidade de vida e saúde mental. Além disso, pode se configurar em uma esfera de iniquidades sociais, produção das relaçóes de poder que representam a condição de precariedade. As concepçôes de uma autora importante acerca da precariedade (12-14) $^{-1}$ remetem o termo a uma condição politicamente construída pela qual determinadas populaçôes são assimetricamente expostas a contextos de violência, perigo, enfermidade, migração forçada, pobreza, ou morte. E, como processo e movimento, a precariedade reforça situaçóes de VS e vice-versa, pois muitas vidas não são consideradas vidas pelo Estado ou grupos de maior poder político e econômico.

Em meio a essa precariedade, o sujeito pode obter meios para conscientização da submissão às ordens de poder e resistir à VS pelo agenciamento. Há, portanto, uma tomada do controle sobre a vida que reverbera na condição de VS, pois há a possibilidade de movimento das relaçôes em direçáo a uma melhor condição de saúde e vida, ou seja, menor vulnerabilidade. Apesar da precariedade tornar e produzir sujeitos invisíveis perante as políticas públicas de saúde, essa concepção de sujeito, para Butler, torna possível a condição da agência, compreendida como potência, capacidade de ação, por se apresentar produtiva para a compressão da ação social, sobretudo de sujeitos subalternos a uma ordem social hegemônica. Butler caracteriza a agência como uma prática de articulação e de ressignificação ao poder de fazer. ${ }^{(12,14)}$

A consciência citada gera as condiçóes de resistência e de reflexividade, permitindo ao sujeito-social se opor aos abusos do poder normalizador que limita e controla os desejos de sua própria possibilidade, produzindo os agenciamentos. ${ }^{(15)}$ Eles não são uma característica exclusivamente individual, mas consubstanciada no contexto social, promotores da saúde e de vidas vivíveis. O sujeito é performativo, ou seja, uma produção ritualizada, uma reiteração ritual de normas, mas que não o determinam totalmente. Essa incompletude possibilita o processo de ruptura e a inscrição de novos significados e, consequentemente, a mudança de práticas e contextos. ${ }^{(12,15)} \mathrm{Ou}$ seja, o sujeito-social resiste para não estar em uma condição de VS ou para não a perpetuar; ele encontra as potencialidades para ressignificar normas, discursos, experiências, vivências e práticas sociais. ${ }^{(15)}$

Assim, observa-se a necessidade de que a intersetorialidade esteja no campo do cuidado em saúde, uma vez que a vulnerabilidade é um constructo que se dá nas relaçóes com diferentes pessoas e em/sobre/com diferentes espaços. Considerando esses aspectos, a promoção da saúde e produção de vida se configuram como pano de fundo importantes nas discussões sobre VS. As primeiras inspiraçôes para o desenvolvimento do conceito VS advieram da necessidade de se pensar a promoçáo da saúde e não apenas a prevenção, estando implícita a intersetorialidade, não se dirigindo à determinada doença ou desordem, mas à produção de vida. (4,12,16-18) $^{-}$

Com base em todos esses elementos discutidos, construiu-se uma (re)definição do conceito de VS. Ela é o ponto de partida para pensar em uma representação do modelo conceitual, fase complexa, pois os elementos essenciais da VS não são hierárquicos nem dissociados, tem elementos diversos, interconectados, múltiplos. Cada um tem sua característica, conceitos e subconceitos, mas só existem na presença do outro, ao mesmo tempo que suas características podem se confundir. É um social-sujeito e um sujeito-social. O que está posto no entremeio 
é de difícil representação e essa transição é quase imperceptível.

Segundo autores, ${ }^{(4)}$ as pessoas não são vulneráveis, elas estão vulneráveis sempre a algo, em algum grau e forma e em certo ponto do tempo e do espaço. No entanto, acredita-se que o sujeito ou coletivo vivencia processos ou está em condição de VS. Não se busca a adjetivação e objetificação, mas as relaçôes, devendo ser repensada, portanto, a utilização do termo vulnerável. ${ }^{(19)}$ Além disso, alguns autores $^{(20)}$ utilizam o termo 'marcador' quando querem caracterizar algum atributo ou situação de VS. Porém, denota uma situação fixada, marcada, de difícil transformação, ou seja, não situacional.

Diferente das teorias, os modelos conceituais representam de forma analógica um conceito. Nesse sentido, há avanço de estudos nessa perspectiva, em que se identificam na literatura ensaios teóricos sobre VS, bem como sua aplicabilidade na construção de instrumentos/escalas. ${ }^{(2,20-24)}$ Então, para dar conta do referencial do esclarecimento, foi produzido um modo de apresentar o conceito. De forma analógica, quando se pensa em uma música e nas suas notas musicais, não se sabe onde encerra uma e inicia a próxima quando as escutamos. Nesse caso, os sentidos humanos não conseguem alcançar a passagem de uma para outra. Assim, construiu-se uma figura que representa a VS nessa perspectiva do entremeio e das relaçóes de poder.

Nessa analogia aos elementos musicais, o sujeito-social compóe um conjunto de notas musicais. Essas compóem uma melodia, a VS, que tem variaçôes harmônicas. Resgatando esses conceitos para a VS, essas variaçóes podem ser traduzidas em um contínuo de condiçóes de precariedade ou de agenciamento. Essas produçóes são resultado da relação entre as notas, ou seja, interação entre os elementos do conceito, estabelecidas por relaçóes de poder na produção da saúde. As condiçôes de precariedade potencializam os processos de vulnerabilidade, enquanto o agenciamento o fragiliza, transformando-os. As vidas então resistem, recriam-se e (re)tornam-se visíveis e vivíveis.

Assim, quando há movimento, há poder e ele não pesa só com a força que diz não ou tem como produto a precariedade, mas ele também permeia, produz coisas, induz ao prazer, forma saber, produz discurso, ou seja, produz vidas potentes, resistentes em processos de agenciamentos. ${ }^{(11)}$

A figura 2 representa o modelo conceitual da VS na perspectiva das múltiplas possibilidades de música que pode ser produzida. As notas musicais são cada um dos conceitos e subconceitos do elemento essencial, onde os diversos tons de azul se configuram, enquanto o sujeito e os tons de verde, o social. Esses estão em relação, mostrada pelas linhas pontilhadas, as quais definem o caráter não permanente ou quase "fixo" daquela interação e que podem mudar a cada vez que entram em contato com outras notas. A resposta dessa relação de poder é o (re)arranjo das notas numa partitura, configurando a melodia do agenciamento, definindo uma fragilização da VS ('diminuição'), ou a melodia da precariedade, potencializando a VS ('aumento'), conformando as diversas possibilidades de música chamadas de VS.

As linhas pontilhadas na precariedade falam da fragilidade e desigualdade das relaçóes entre os elementos, resultando em processos de potencialização da VS. No entanto, com possibilidade de mudança para a transformação dessas situaçóes. As linhas contínuas remetem a relaçôes mais fortes, no sentido de haver maior qualidade destas e que reforçam a promoção da saúde, simultaneamente ou posteriores aos processos de fragilização da VS. As relações ocorridas a partir da precariedade ou do agenciamento também podem se reorganizar, dando lugar a outras relaçôes de poder e, consequentemente, a outros processos de VS e outras respostas, fenômeno que pode ocorrer em sequência ou ao mesmo tempo, o que caracteriza e ratifica a VS como um fenômeno diverso, dinâmico e múltiplo.

\section{Conclusão}

O modelo conceitual proposto esclarece o conceito de VS, pois seus componentes são definidos e relacionados em analogia à música. Além da descrição do fenômeno e identificação do elemento essencial, foi possível conhecer os principais atributos (conceitos e subconceitos) do sujeito-social, de forma que se pudesse conjecturar quando a VS estava produ- 
zindo precariedade ou agenciamentos devido uma determinada situação. $\mathrm{O}$ modelo fornece subsídios à elaboração de pesquisas na área da saúde coletiva e ao futuro desenvolvimento de teorias de médio ou longo alcance da vulnerabilidade em saúde. $\mathrm{O}$ modelo proposto é mais um passo para dinamizar e estimular o uso coerente do conceito pelos pesquisadores e profissionais da saúde, tomando-o como um vir a ser, como uma condição da vida humana na perspectiva sujeito-social.

\section{Agradecimentos}

À Coordenação de Aperfeiçoamento de Pessoal de Nível Superior (CAPES; bolsa de doutorado para RSF).

\section{Colaborações}

Florêncio RS e Moreira TMM declaram que contribuíram com a concepção do estudo, análise e interpretação dos dados, redação do artigo e aprovação da versão final a ser publicada.

\section{Referências}

1. Oviedo RA, Czeresnia D. 0 conceito de vulnerabilidade e seu caráter biossocial. Interface (Botucatu). 2015;19(53):237-250.

2. Schumann LR, Moura LB. Vulnerability synthetic indices: a literature integrative review. Ciênc saúde coletiva. 2015;20(7):2105-20.

3. Feitosa MZ, Sousa LC, Paz AF, Barreto EH, Bomfim ZÁ. Afetividade, território e vulnerabilidade na relação pessoa-ambiente: um olhar ético político. Fractal. Rev Psicol. 2018;30(2):196-203.

4. Ayres JR, Calazans GJ, Saletti Filho HC, França Júnior I. Risco, vulnerabilidade e práticas de prevenção e promoção da saúde. In: Campos GW, Minayo MC, Akerman M, Drumont Júnior M, Carvalho YM, organizadores. Tratado de saúde coletiva. 2a ed. São Paulo: Hucitec; 2012.

5. Barbosa KT, Oliveira FM, Fernandes MD. Vulnerability of the elderly: a conceptual analysis. Rev Bras Enferm. 2019;72 Suppl 2:337-44.
6. Mann J, Tarantola DJ, Netter TW. Aids in the word. Cambridge: Harvard University Press; 1992.

7. Meleis Al. Theoretical nursing: development and progress. 5th ed. Pennsylvania: Lippincott Williams \& Wilkins; 2012.

8. Florêncio RS, Moreira TM, Pessoa VL, Cestari VR, Silva VM, Rabelo SM, et al. Mapping studies on vulnerability in health: a scoping review. Research, Society and Development. 2020;9(10):e2079108393.

9. Florêncio RS. Vulnerabilidade em saúde: uma clarificação conceitual [tese]. Fortaleza: Universidade Estadual do Ceará; 2018.

10. Pasquali L. Psicometria: teoria dos testes na psicologia e na educação. Petrópolis: Vozes; 2003.

11. Foucault M. Microfísica do poder. Rio de Janeiro: Graal; 2011. 295 p.

12. Butler J. Frames of War. When is life grievable. New York: Verso; 2009.

13. Butler J. Vida precária. Contemporânea: Rev Sociol UFSCar. 2011;1:13-33.

14. Butler J. Cambio del sujeto: La política de la resignificación radical de Judith Butler. Casale R, Chiachio C., organizadores. Máscaras del deseo: una lectura del deseo en Judith Butler. Buenos Aires: Catálogos; 2009. pp. 65-111.

15. Butler J. Mecanismos psíquicos del poder: teorías sobre la sujeción. 2a ed. Madrid: Ediciones Cátedra; 2010.

16. Silva Júnior JB. Health promotion: necessary and urgent action in the Americas [editorial]. Ciênc Saúde Coletiva. 2019;24(11):3994.

17. Sonaglio RG, Lumertz J, Melo RC, Rocha CM. Promoção da saúde: revisão integrativa sobre conceitos e experiências no Brasil. J Nurs Health. 2019;9(3):e199301.

18. Vieira LS, Belisário SA. Intersectoriality in the promotion of school in health: a study of the Health in School Program. Saúde Debate 2018;42(Spe 4):120-33.

19. Chaves SE, Ratto CG. Fronteiras da formação em saúde: notas sobre a potência da vulnerabilidade. Interface (Botucatu). 2018;22(64):18998.

20. Padoveze MC, Juskevicius LF, Santos TR, Nichiata LI, Ciosak SI, Bertolozzi MR. The concept of vulnerability applied to Healthcareassociated Infections. Rev Bras Enferm. 2019;72(1):299-303.

21. de Groot N, Bonsel GJ, Birnie E, Valentine NB. Towards a universal concept of vulnerability: broadening the evidence from the elderly to perinatal health using a Delphi approach. PLoS One. 2019;14(2):e0212633.

22. Cestari VR, Moreira TM, Pessoa VL, Florêncio RS, Silva MR, Torres RA. The essence of care in health vulnerability: a Heideggerian construction. Rev Bras Enferm. 2017;70(5):1112-6.

23. Jesus IT, Orlandi AA, Grazziano ES, Zazzetta MS. Frailty of the socially vulnerable elderly. Acta Paul Enferm. 2017;30(6):614-20.

24. Maffacciolli R, Oliveira DL. Challenges and perspectives of nursing care to vulnerable populations. Rev Gaúcha Enferm. 2018;39:e20170189. 
Florêncio RS, Moreira TM

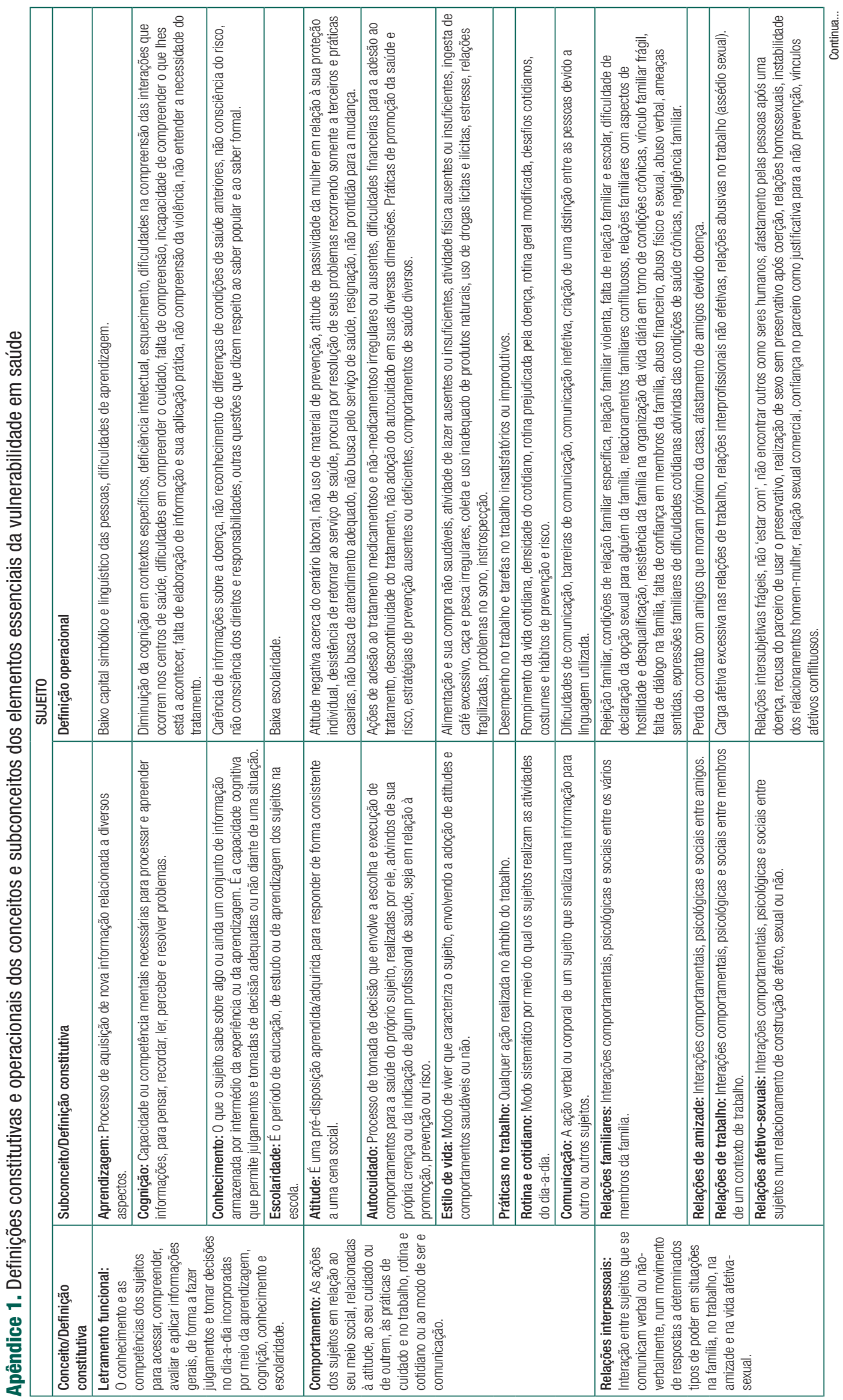




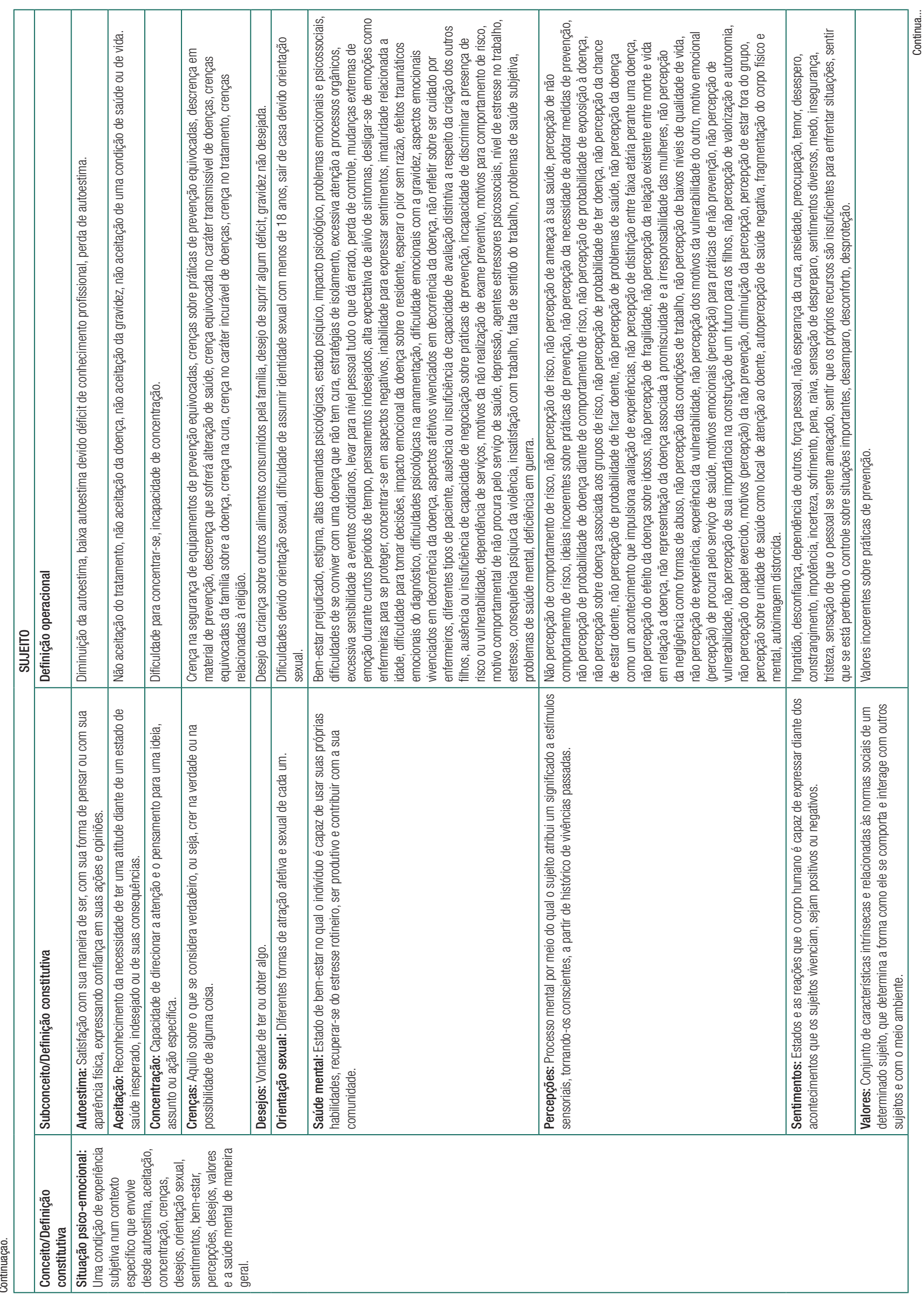

10 Acta Paul Enferm. 2021; 34:eAPE00353. 
Florêncio RS, Moreira TM

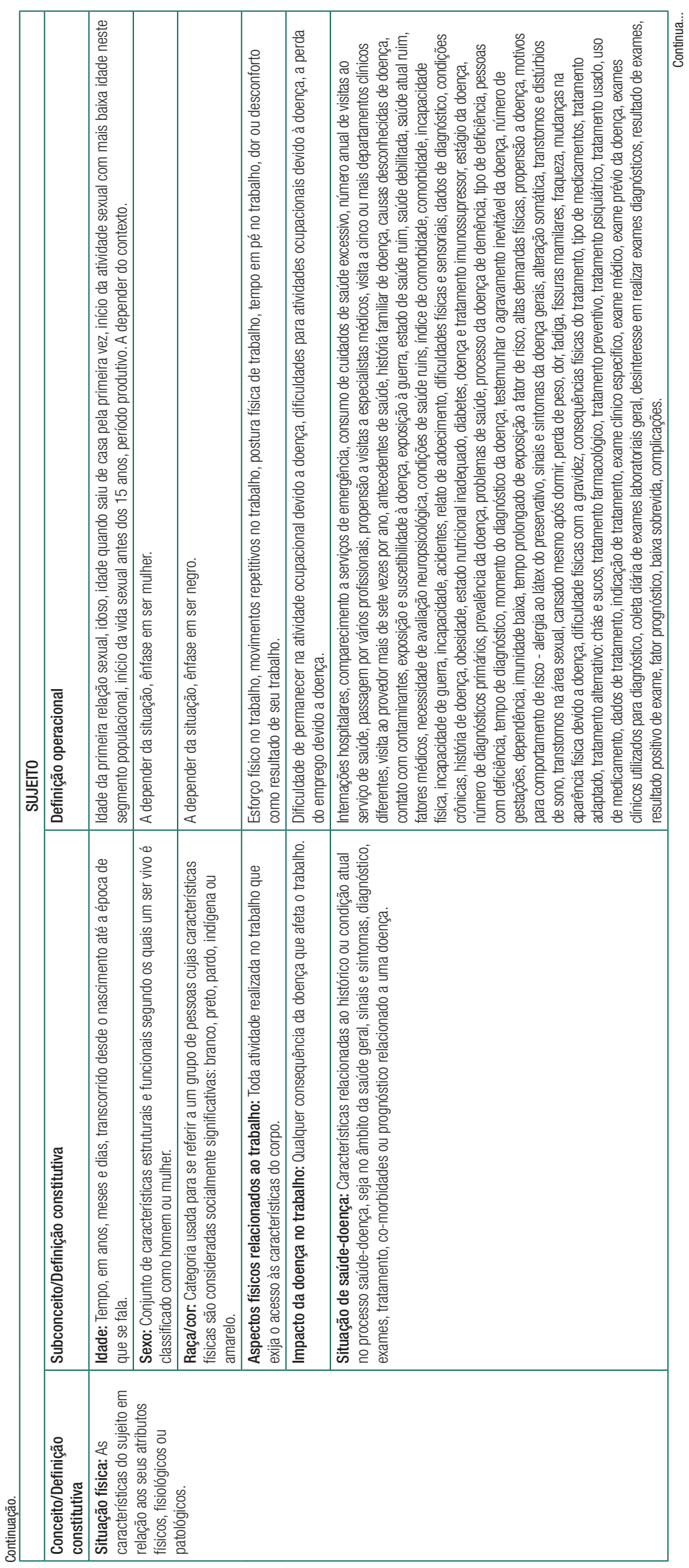




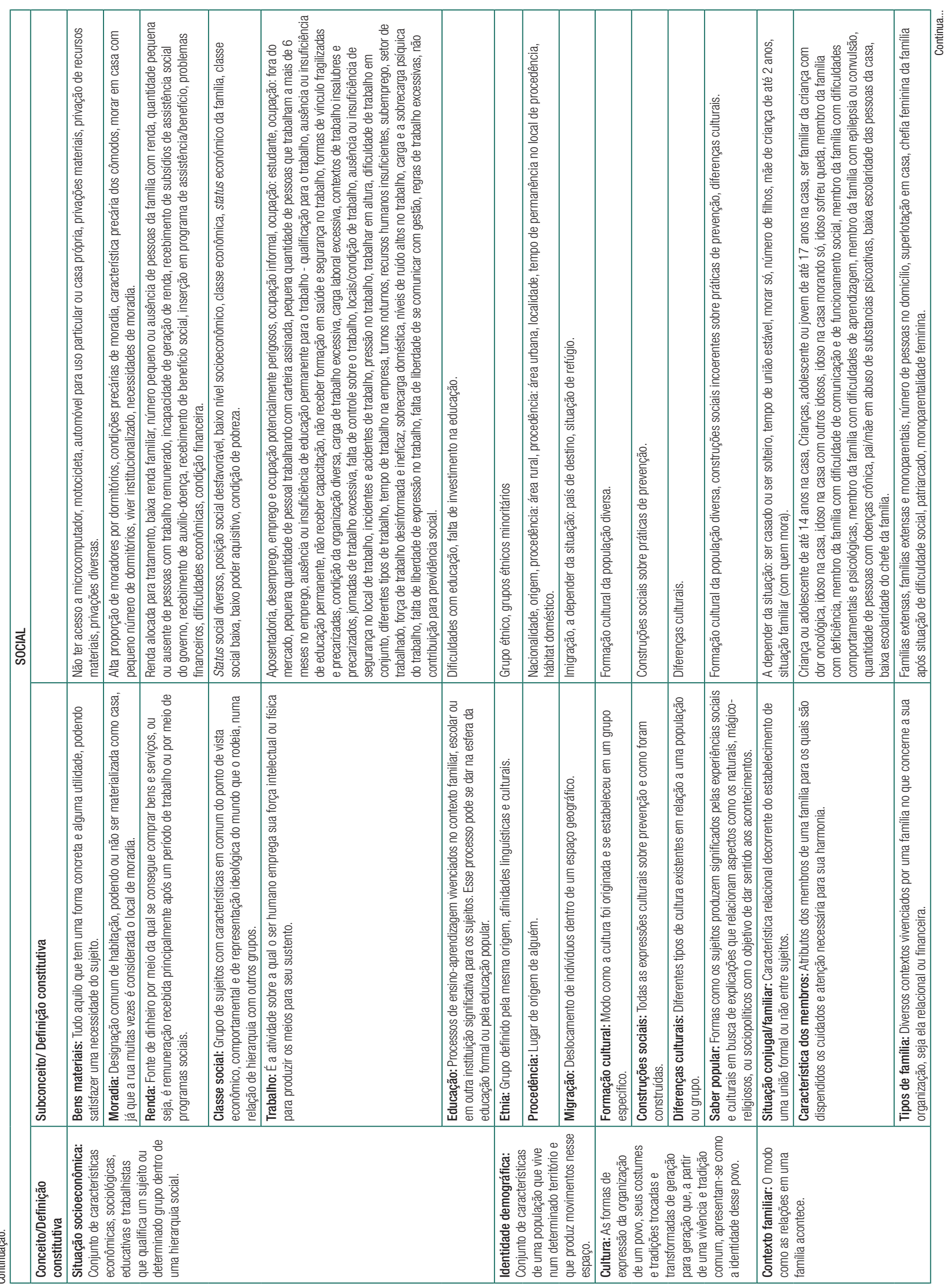




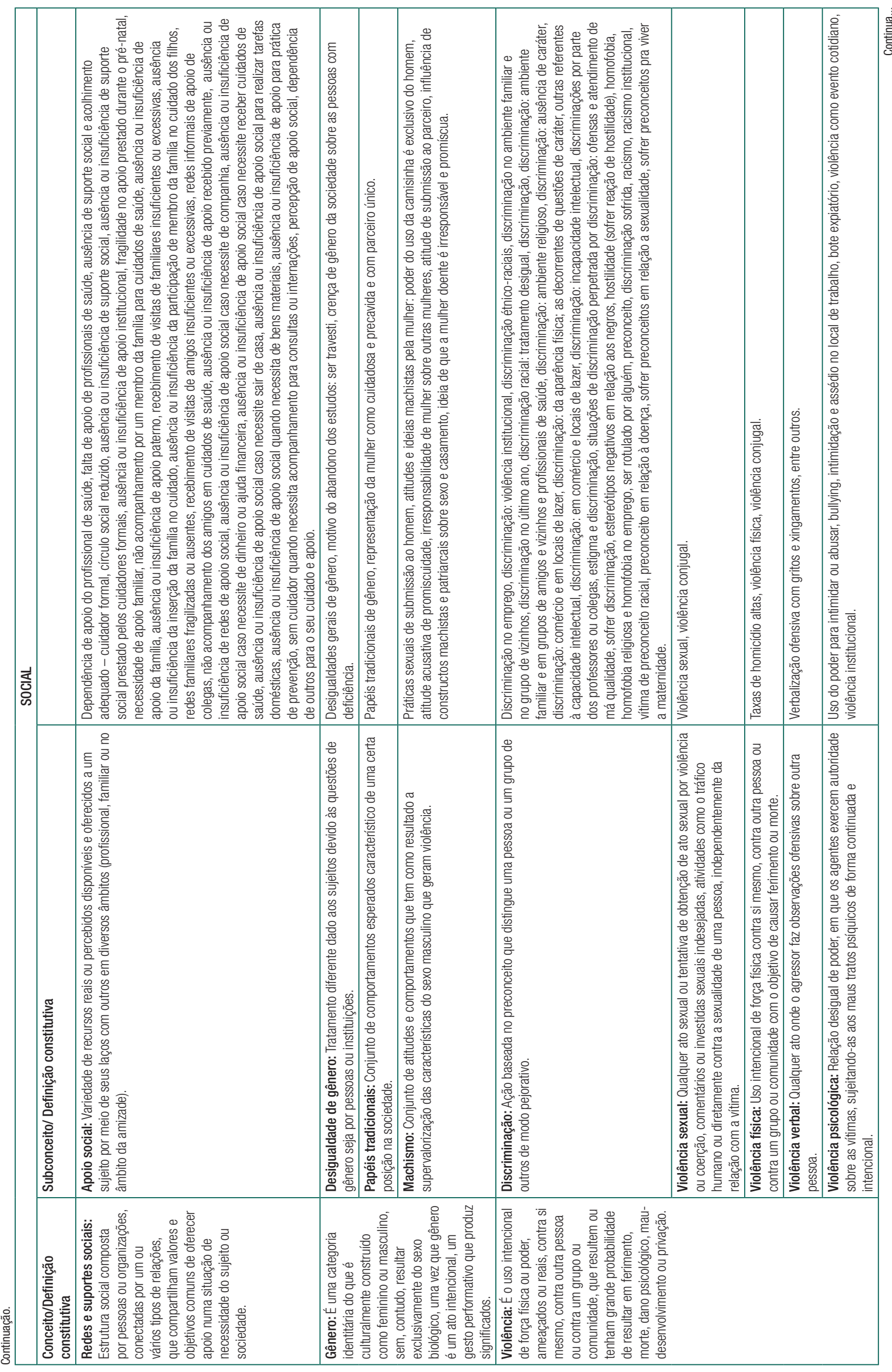




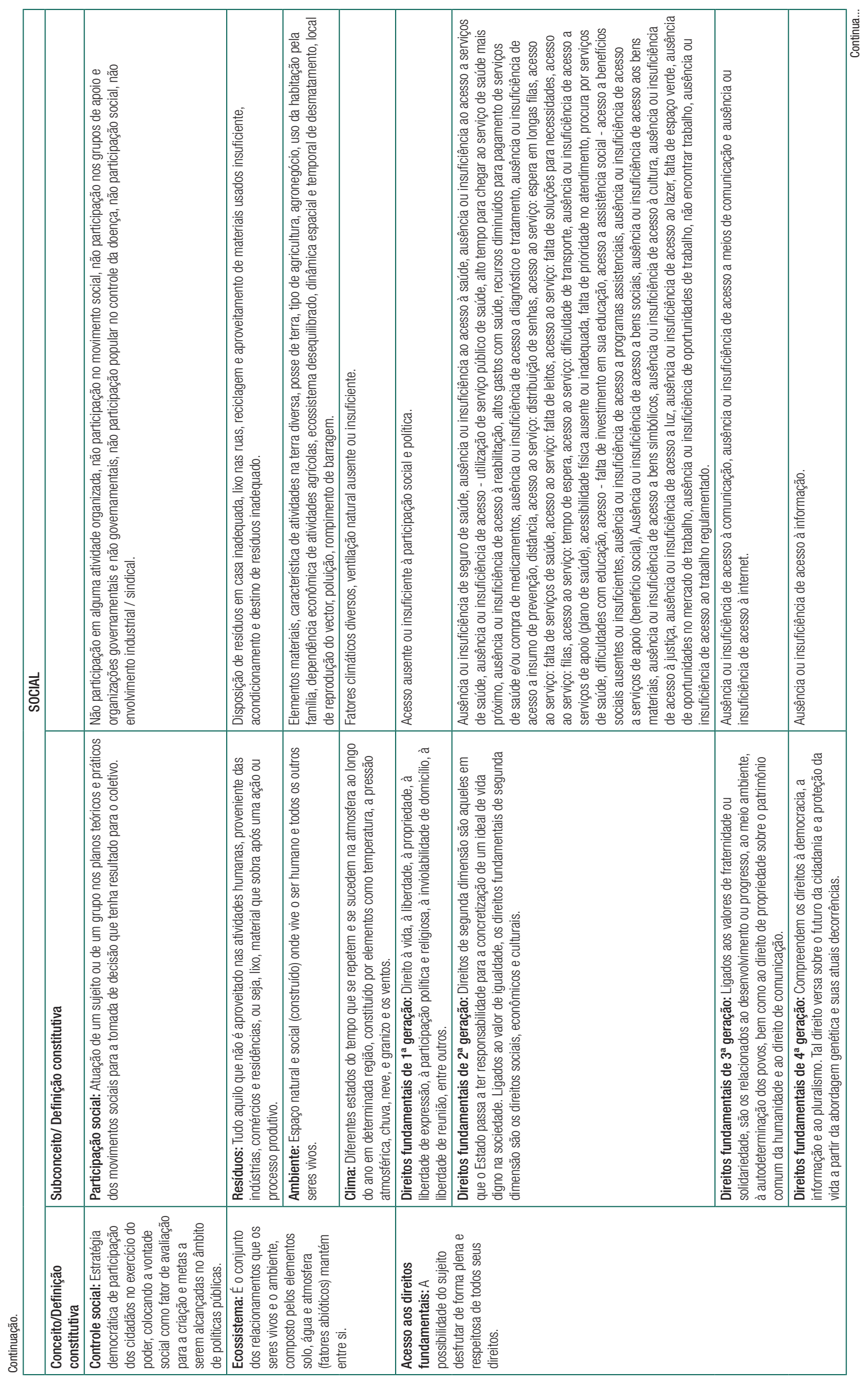




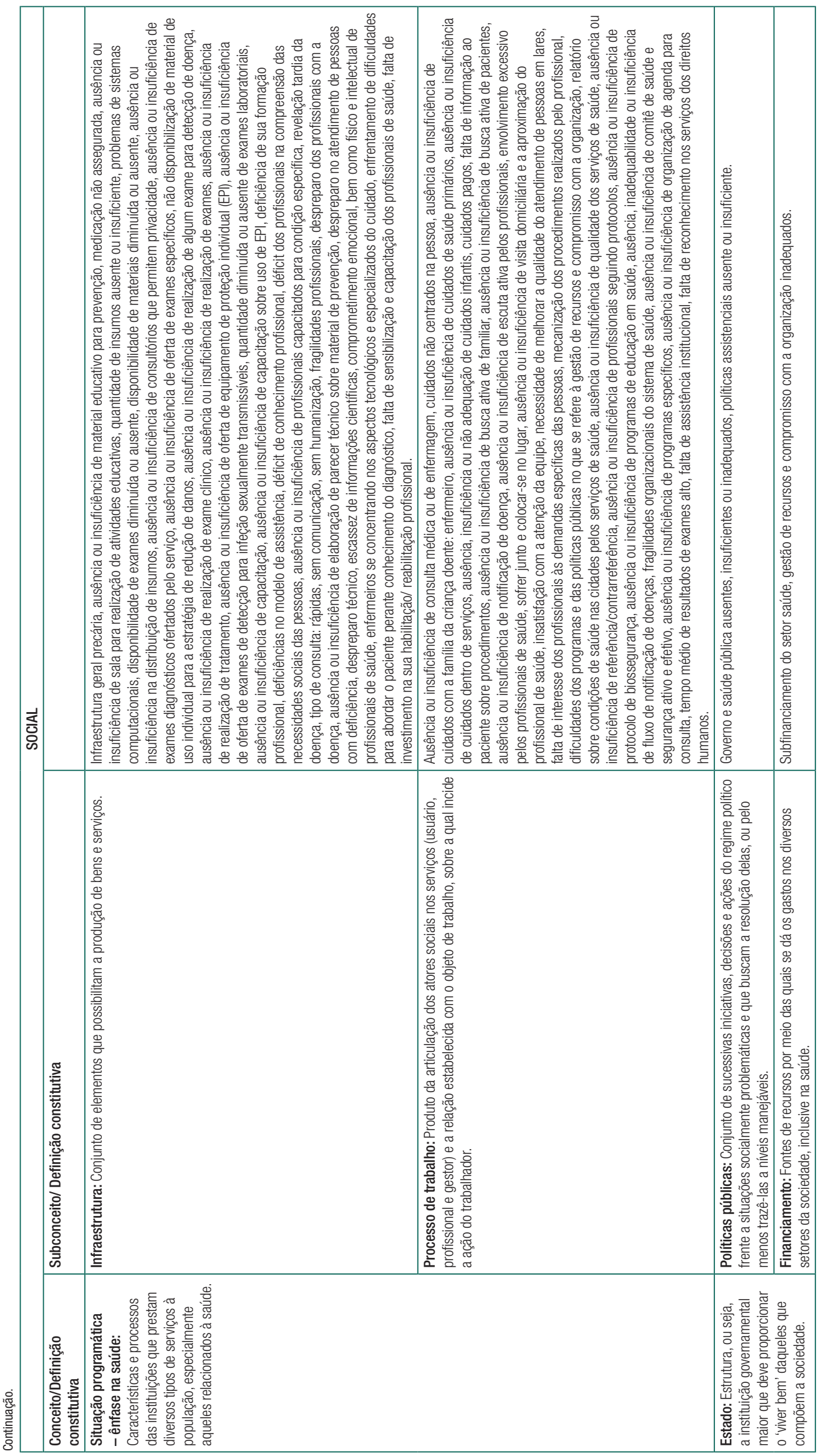

